\title{
Characterization of Immunotoxins Active against Ovarian Cancer Cell Lines
}

Robert Pirker, David J. P. FitzGerald, Thomas C. Hamilton, Robert F. Ozols, Walter Laird, Arthur E. Frankel, Mark C. Willingham, and Ira Pastan

Laboratory of Molecular Biology and Medicine Branch, National Cancer Institute, Bethesda, Maryland 20205; and Cetus Corporation, Emeryville, California 94608

\begin{abstract}
The purpose of the present study was to develop immunotoxins directed against human ovarian carcinoma cells. Four monoclonal antibodies (260F9, 454C11, 280D11, and 245E7) were chosen because they were found to bind to various ovarian carcinoma cell lines. These antibodies were covalently linked to either Pseudomonas exotoxin (PE) or ricin A chain (RTA), and the conjugates were tested against five ovarian cancer cell lines (OVCAR-2, -3, -4, -5; A1847). The ability of the immunotoxins to inhibit both protein synthesis and colony formation was evaluated. Qualitatively similar results were obtained for both types of assays. Usually, PE conjugates were more toxic than their corresponding RTA conjugates. 454C11-PE was very toxic for all ovarian carcinoma lines, whereas 454C11-RTA had low activity. Both 260F9-PE and 260F9-RTA were active in all OVCAR cell lines but not in A1847 cells. 280D11-PE was toxic for OVCAR-4; otherwise, 280D11-PE and RTA conjugates of both 280D11 and 245E7 had little activity. Specificity of immunotoxin action was shown by competition by excess antibody, nontoxicity in nontarget cells, and inactivity of an irrelevant immunotoxin. To investigate the basis of antibody-dependent differences in activity of the various immunotoxins, antibody uptake was studied in OVCAR-2 cells, and the results indicate that antibody internalization is one important factor in the activity of immunotoxins.
\end{abstract}

\section{Introduction}

The availability of monoclonal antibodies (1) has opened new possibilities for cancer therapy because they can be used for targeting drugs $(2)$ or toxins $(3,4)$ to cancer cells. We have begun to study the effects of antibody-toxin conjugates on human ovarian carcinoma cell lines in order to explore their potential usefulness as an alternative therapeutic approach to human ovarian cancer. Ovarian cancer is difficult to treat because these tumor cells often develop resistance to a broad spectrum of cytotoxic drugs (5). These cells should be sensitive to antibodytoxin conjugates because the mechanism by which toxins kill cells is different from the mechanism of action of conventional chemotherapeutic agents. Because ovarian cancer remains localized in the peritoneal cavity even late in the course of the disease, immunotoxins could be administered intraperitoneally

Address correspondence and reprint requests to Dr. Pastan, Laboratory of Molecular Biology, National Cancer Institute, Building 37, Room 4E 16, Bethesda, MD 20205.

Received for publication 23 January 1985 and in revised form 15 May 1985.

J. Clin. Invest.

(c) The American Society for Clinical Investigation, Inc.

0021-9738/85/09/1261/07 \$1.00

Volume 76, September 1985, 1261-1267 and, due to lymphatic obstruction (6), would only be cleared slowly from the peritoneal cavity. Thus, high local concentrations of the agent could be achieved and maintained, and systemic toxicity could be limited.

We recently described the effect of an antitransferrin receptor (anti-TFR) ${ }^{1}$-Pseudomonas exotoxin (PE) conjugate on five human ovarian carcinoma cell lines (7). Although this immunotoxin inhibited protein synthesis in all cell lines tested, there were quantitative differences in the response of various cell lines which were explained by differences in the binding and internalization of the immunotoxin and by different sensitivities to the toxin. Currently, it is not known whether the expression of transferrin receptors on normal tissues (8) would exclude the clinical use of an antitransferrin receptor conjugate. Therefore, we are also investigating the activity of other immunotoxins. The monoclonal antibodies used in this study were originally obtained against human breast cancer cells (9) and, when conjugated to ricin A chain (RTA), gave immunotoxins active against human breast cancer cell lines (10). Because these antibodies were found to cross-react with some other carcinomas, and in particular with ovarian carcinomas (9), we used them to construct immunotoxins directed against human ovarian carcinoma cells by linking these antibodies to either PE or RTA. Both PE and RTA must be delivered to the cytoplasm, where they inhibit protein synthesis either by inactivating elongation factor 2 through ADP-ribosylation, as in the case of PE (11), or by blocking the ribosomal binding site for elongation factor 2 , as in the case of RTA (12). In the present paper, we describe the cytotoxic effects of these antibody-toxin conjugates on human ovarian carcinoma cell lines.

\section{Methods}

Cell culture. National Institutes of Health/OVCAR-2, -3, -4, and -5 are isolates from the malignant ascites of patients with ovarian carcinoma $(13,14)$. The ovarian cancer cell line A1847 was obtained from Dr. S. Aaronson (National Cancer Institute, Bethesda, MD). The ovarian cells were grown in RPMI medium 1640, 10\% fetal bovine serum, $10 \mu \mathrm{g} / \mathrm{ml}$ insulin, and penicillin-streptomycin. MCF-7 human breast cancer cells were cultivated in Improved MEM (modified Eagle's medium) Zinc Option Medium, $10 \%$ fetal bovine serum, and penicillin-streptomycin. KB cells were grown in Dulbecco's modified Eagle's medium (DME), $10 \%$ calf serum, glutamine, and penicillin-streptomycin. Tissue culture media, sera, glutamine, and antibiotics were purchased from Gibco Laboratories, Grand Island, NY, and insulin was obtained from Elanco Products Co., Indianapolis, IN. For protein synthesis inhibition assays, cells were plated at $2 \times 10^{5}$ cells/35-mm dish $1 \mathrm{~d}$ before use. Before adding immunotoxins, cells were washed twice with DME containing bovine serum albumin $(2 \mathrm{mg} / \mathrm{ml})$ (DME-BSA).

1. Abbreviations used in this paper: Anti-TFR, antibody against the transferrin receptor, DME, Dulbecco's modified Eagle's medium; DTNB; 5,5'-dithio-bis(2-nitrobenzoic acid); HPLC, high performance liquid chromatography; PE, Pseudomonas exotoxin; RTA, ricin A chain. 


\section{0 minutes}

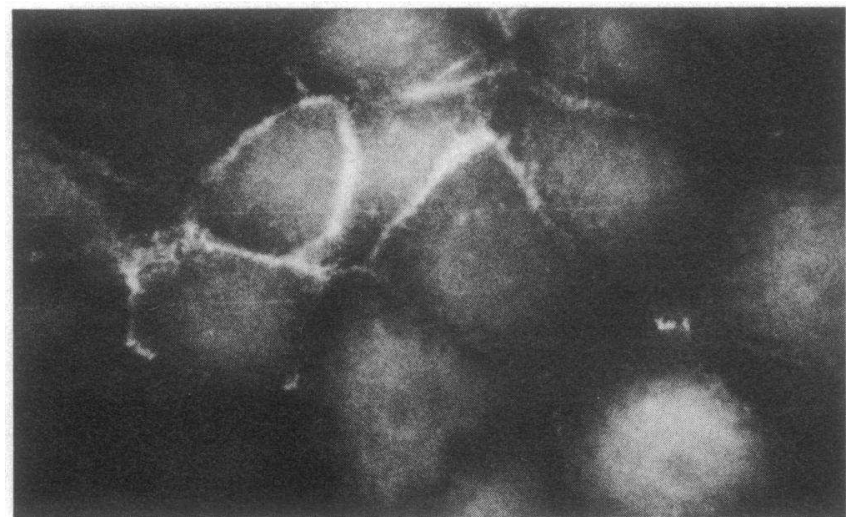

ANTI-TFR

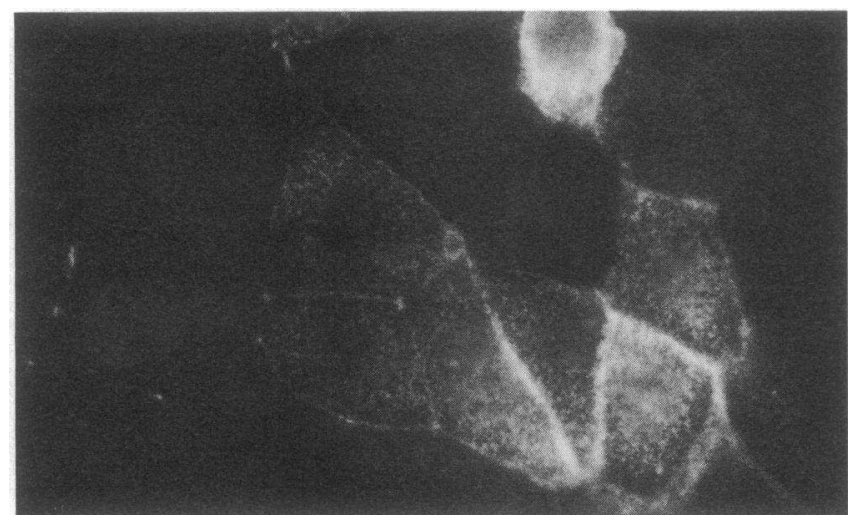

\section{$260 F 9$}

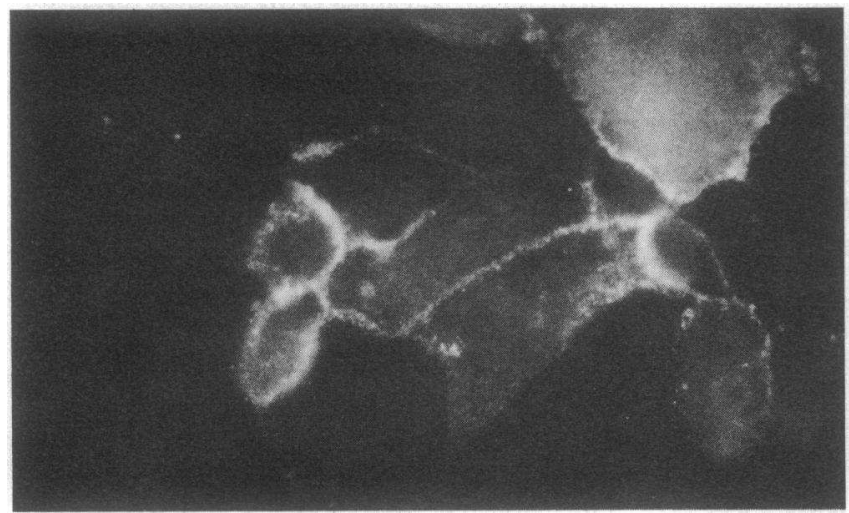

\section{1}

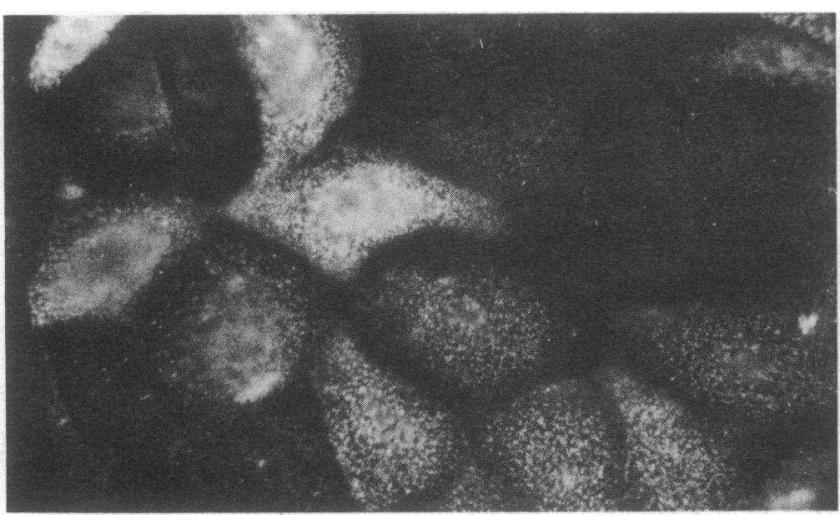

\section{$454 C 11$}

Figure 1. Binding and internalization of monoclonal antibodies by OVCAR-2 cells. Cells were incubated with antibodies $(10 \mu \mathrm{g} / \mathrm{ml})$ at $4^{\circ} \mathrm{C}$ for $1 \mathrm{~h}$. Then cells were warmed up to $37^{\circ} \mathrm{C}$ for 0 or $60 \mathrm{~min}$, fixed with $3.7 \%$ formaldehyde, permeabilized with Triton X-100, and then incubated with rhodamine-labeled goat anti-mouse IgG for 15

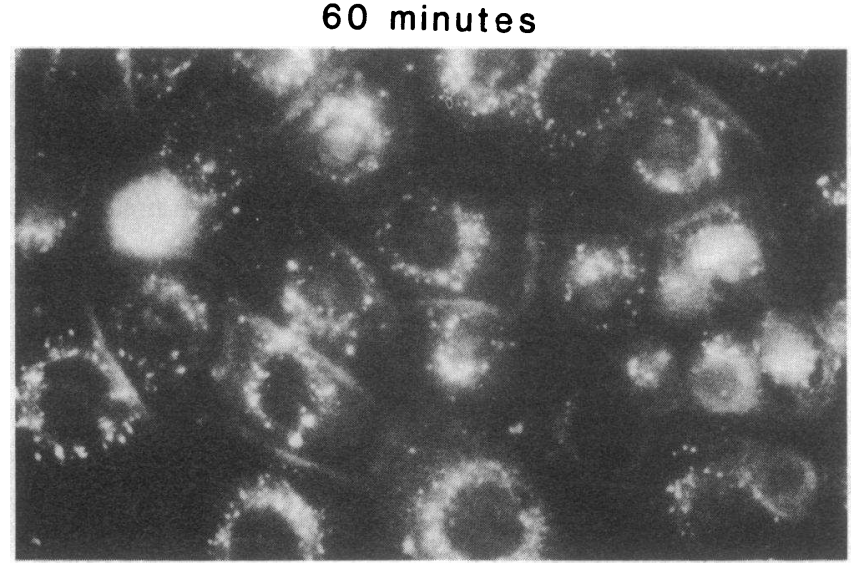

\section{ANTI-TFR}

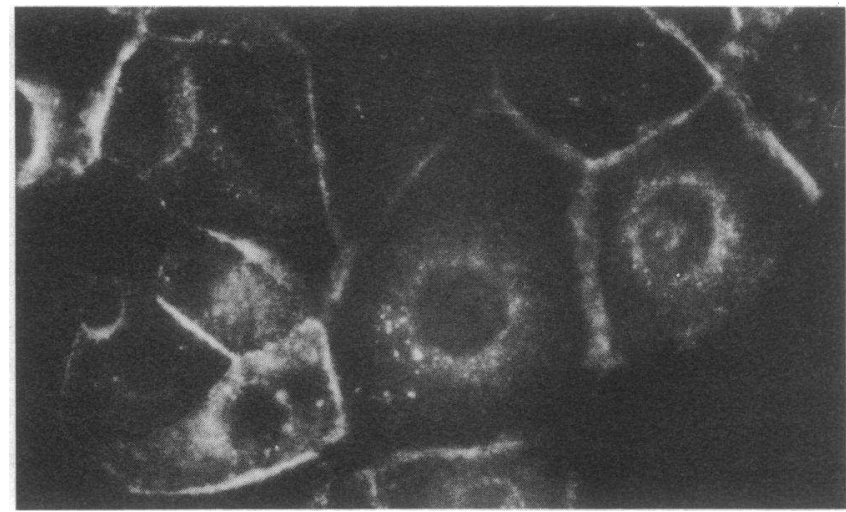

$260 F 9$

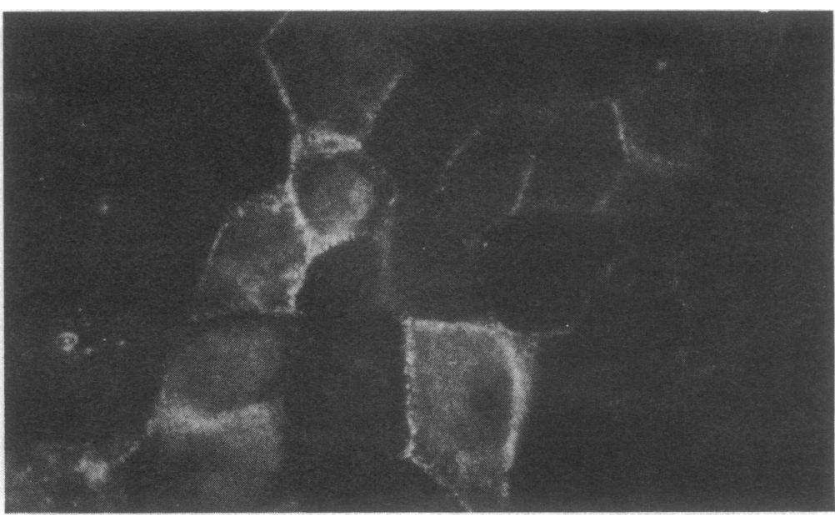

280D11

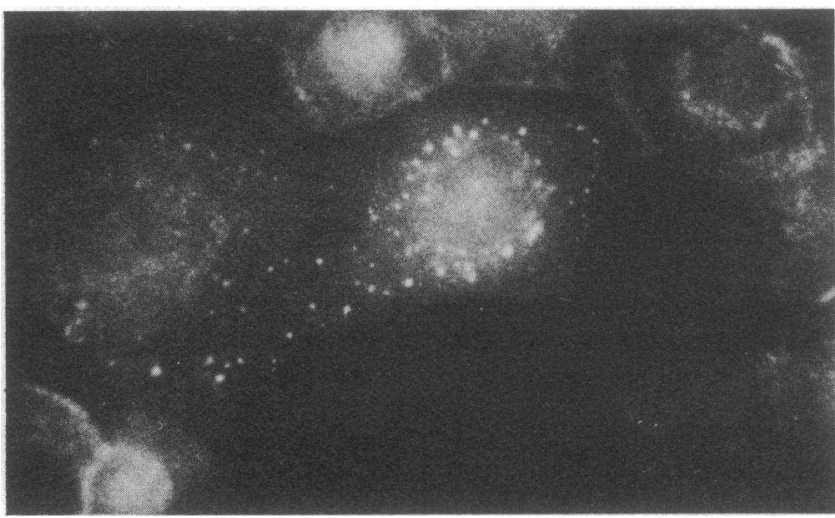

$454 C 11$

min at room temperature. Each of the antibodies bound to the OVCAR-2 cells (left). After the warm-up, anti-TFR, 260F9, and 454C11 were detected intracellularly, whereas no internalization of 280D11 could be observed (right). 
Antibodies. Monoclonal antibodies were obtained as described (9). In addition to binding to human breast cancer cells, some of the antibodies were also found to bind to other carcinomas (9). Four of these antibodies (260F9, 454C11, 280D11, and 245E7) were chosen for the present study because they were found to react with ovarian carcinoma cell lines as assessed by indirect immunofluorescence. The antibody $454 \mathrm{C} 11$ is of the IgG-2a subclass, and the others are of the IgG-1 subclass. Anti-TFR was purified from the ascites of nude mice bearing HB21 (American Type Culture Collection, Rockville, MD) as previously described (7).

Antibody-toxin conjugates. PE was a gift of Dr. S. Leppla (Ft. Detrick, Frederick, MD). PE conjugates were constructed and purified by a modification of a method previously described (7). PE $(30 \mathrm{nmol})$ was reacted with 5,000 nmol 2-iminothiolane- $\mathrm{HCl}$ (Pierce Chemical Co., Rockford, IL) and $500 \mathrm{nmol} \mathrm{NAD}^{+}$in $1 \mathrm{ml} 0.1 \mathrm{M}$ phosphate buffer (pH 8.0) containing $1 \mathrm{mM}$ EGTA at $37^{\circ} \mathrm{C}$ for $1 \mathrm{~h}$. The derivatized PE was then separated from the reactants using high performance liquid chromatography (HPLC) and activated by the addition of 5,5'-dithio-bis(2-nitrobenzoic acid) (DTNB) to a final concentration of $1 \mathrm{mM}$. Antibodies (40$50 \mathrm{nmol}$ ) were incubated with $100-200 \mathrm{nmol} 2$-iminothiolane- $\mathrm{HCl}$ in $0.75 \mathrm{ml} 0.1 \mathrm{M}$ phosphate buffer $(\mathrm{pH} 8.0)$ containing $1 \mathrm{mM}$ EGTA at $37^{\circ} \mathrm{C}$ for $1 \mathrm{~h}$. Then antibodies were reacted with the activated $\mathrm{PE}$, and the conjugates were purified using HPLC as described (7). A peak containing a one-to-one conjugate of PE with the antibody was recovered and used for all studies described below. RTA conjugates were prepared by incubating RTA with antibody which had been activated by incubation with 2-iminothiolane and DTNB. They were purified by gel filtration chromatography to remove unreacted RTA and affinity chromatography to remove unreacted antibody. A detailed description of this procedure and the resulting product will be published (Bloch, W., R. Ferris, D. Birch, and J. Ellingson, manuscript in preparation).

Protein synthesis assay. Inhibition of protein synthesis was used to measure the activity of the immunotoxins. Cells were incubated with DME-BSA containing various concentrations of immunotoxins at $37^{\circ} \mathrm{C}$ for $24 \mathrm{~h}$ and then assayed for incorporation of $\left[{ }^{3} \mathrm{H}\right]$ leucine (New England Nuclear, Boston, MA; specific activity, $140.8 \mathrm{Ci} / \mathrm{mmol}$ ) into TCA-insoluble material as described previously (7). Mean values of duplicates were expressed as a percentage of controls that did not receive immunotoxins.

Colony formation assay. About 500 cells were plated in a $60-\mathrm{mm}$ dish containing $5 \mathrm{ml}$ medium and various concentrations of immunotoxins. The cells were incubated at $37^{\circ} \mathrm{C}$ for $8-14 \mathrm{~d}$. Then, the medium was removed and the colonies were stained with $0.5 \%$ methylene blue in ethanol/water (1:1). After washing and drying, the colonies were counted and the results were expressed as a percentage of the controls that were incubated without immunotoxin.

Binding and internalization of antibodies assessed by indirect im- munofluorescence of OVCAR-2 cells. $1 \mathrm{~d}$ after plating, cells were washed with cold Dulbecco's phosphate-buffered saline (PBS) (Gibco Laboratories) containing bovine serum albumin $(2 \mathrm{mg} / \mathrm{ml}$ ) (PBS-BSA), and then incubated with $10 \mu \mathrm{g}$ antibody (anti-TFR, 260F9, 280D11, and $454 \mathrm{C} 11$ ) in $1 \mathrm{ml}$ PBS-BSA at $4^{\circ} \mathrm{C}$ for $1 \mathrm{~h}$. Then the cells were washed, incubated in DME-BSA at $37^{\circ} \mathrm{C}$ for 0 or $60 \mathrm{~min}$, fixed with $3.7 \%$ formaldehyde (15 min, room temperature), washed, permeabilized with $0.1 \%$ Triton X-100 (5 min, room temperature), washed, and incubated with rhodamine-labeled goat anti-mouse IgG (Jackson ImmunoResearch Laboratories, Avondale, PA) at room temperature for $15 \mathrm{~min}$. After washing, the cells were examined using a Zeiss RA microscope (Carl Zeiss, Inc., Thornwood, NY) equipped with rhodamine epifluorescence optics and a 63 times, numerical aperture 1.4, oil planapochromat objective. Photographs were prepared using Kodak Tri-X film (Eastman Kodak Co., Rochester, NY) and Diafine (Acufine, Inc., Chicago, IL) development.

\section{Results}

Effect of immunotoxins on protein synthesis. From a bank of monoclonal antibodies prepared against human breast cancer cells (9), four antibodies that reacted strongly with the ovarian cancer cell lines, as assessed by indirect immunofluorescence (Fig. 1 and data not shown), were selected for further study. Immunotoxins were constructed by linking each antibody to either PE or RTA. In the cases of 260F9, 454C11, and 280D11, both PE and RTA conjugates were studied; with 245E7, only RTA conjugates were investigated. The activity of each immunotoxin was initially assessed by measuring inhibition of protein synthesis on five ovarian and two nonovarian cell lines. Results from a representative experiment are shown in Figs. 27 , and the average $\operatorname{ID}_{50}$ values of all experiments are provided in Table I.

Fig. 2 shows experiments in which OVCAR-2 cells were incubated with various immunotoxins. 454C11-PE, 260F9-PE, and 260F9-RTA were very active, with ID $_{50}$ values (Table I) of 2 $\mathrm{ng} / \mathrm{ml}$ for $454 \mathrm{C} 11-\mathrm{PE}, 3 \mathrm{ng} / \mathrm{ml}$ for $260 \mathrm{~F} 9-\mathrm{PE}$, and $38 \mathrm{ng} / \mathrm{ml}$ for 260F9-RTA. The unconjugated antibody competed for the toxicity of the corresponding immunotoxin. 280D11-PE inhibited protein synthesis only at concentrations $>100 \mathrm{ng} / \mathrm{ml}$. RTA conjugates of either 454C11, 280D11, or 245E7 showed little activity (Fig. 2 and Table I).

For OVCAR-3 cells (Fig. 3), 454C11-PE was very active;

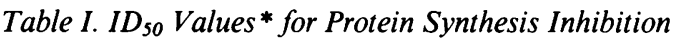

\begin{tabular}{lcccccrrr}
\hline Cells & 260F9-PE & 260F9-RTA & 454C11-PE & 454C11-RTA & 280D11-PE & 280D11-RTA & 245E7-RTA & RTA \\
\hline OVCAR-2 & 3 & 38 & 2 & $>1,000$ & 835 & $>5,000$ & $>5,000$ & 3,900 \\
OVCAR-3 & 42 & 92 & $4 \ddagger$ & $>1,000$ & 805 & 800 & $>5,000$ & 1,200 \\
OVCAR-4 & 5 & 29 & 1 & $>1,000$ & 54 & 2,700 & $>5,000$ & 2,200 \\
OVCAR-5 & 17 & 36 & 10 & $>1,000$ & 3,450 & $>4,000$ & 5,000 & 4,200 \\
A1847 & 385 & $>1,000 \ddagger$ & 3 & $>1,000$ & 2,200 & $>5,000$ & $>5,000$ & ND\$ \\
MCF-7" & 2 & 42 & $<10 \ddagger$ & $1,000 \ddagger$ & 9 & 70 & $230 \ddagger$ & ND\$ \\
KB & 660 & $28,000 \ddagger$ & $15 \ddagger$ & $>1,000$ & 1,200 & 19,000 & $>5,000$ & 1,400 \\
& & & & & & & &
\end{tabular}

Cells were incubated with immunotoxins at $37^{\circ} \mathrm{C}$ for $24 \mathrm{~h}$ and then assayed for protein synthesis. Each experiment was done in duplicates which varied by $<10 \%$. Concentrations of the immunotoxins leading to $50 \%$ inhibition of protein synthesis (ID (I0 $_{50}$ values) were determined. If not otherwise mentioned, the values shown in the table represent mean values of at least two experiments. Results for RTA are from a 12-h incubation assay, and results for both native PE and derivatized PE have been published previously (7). ${ }^{*}$ Values are given in nanograms per milliliter. $\ddagger$ Results from one experiment. $§ \mathrm{ND}$, not done. " A manuscript by Dr. M. J. Bjorn et al., Cetus Corp., describing in detail the activity of these immunotoxins on MCF-7 cells is in preparation. 


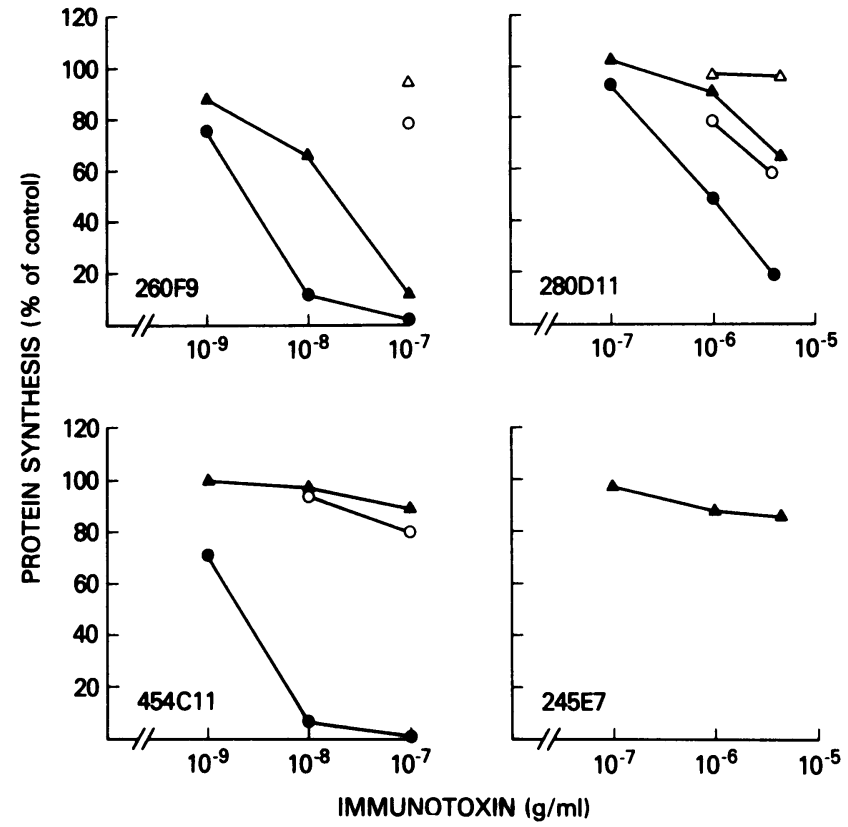

Figure 2. Inhibition of protein synthesis by immunotoxins in OVCAR-2 cells. Cells were incubated with immunotoxins in the absence (closed symbols) or presence (open symbols) of excess unconjugated antibody at $37^{\circ} \mathrm{C}$ for $24 \mathrm{~h}$ and then assayed for protein synthesis. Mean values of duplicates are expressed as percentage of controls that did not receive immunotoxins. The antibodies used for constructing immunotoxins are shown in the lower left corner of each part of the figure. Open symbols represent incubations with immunotoxins in the presence of excess corresponding antibody: 100-fold excess of 260F9 for $260 \mathrm{~F} 9$ conjugates, 10 -fold excess of $280 \mathrm{D} 11$ for $280 \mathrm{D} 11$ conjugates, and 50-fold excess of $454 \mathrm{C} 11$ for $454 \mathrm{C} 11$ conjugates. $\bullet, \mathrm{O}, \mathrm{PE}$ conjugates; $\Delta, \Delta$, RTA conjugates. conjugates of 260F9 showed intermediate activity, with 260F9PE being slightly more active than 260F9-RTA. 280D11 conjugates and RTA conjugates of either $454 \mathrm{C} 11$ or $245 \mathrm{E} 7$ inhibited protein synthesis only at high concentrations $\left(\right.$ ID $_{50}$ values $\geqslant 800$ $\mathrm{ng} / \mathrm{ml}$ ). Fig. 4 shows the results for OVCAR- 4 cells. These cells were very sensitive to 260F9-PE and to 454C11-PE. 260F9-RTA and 280D11-PE showed intermediate activity, whereas RTA conjugates of either $454 \mathrm{C} 11,280 \mathrm{D} 11$ or $245 \mathrm{E} 7$ antibodies had low activity. For OVCAR-5 cells (Fig. 5), 454C11-PE was very active. Conjugates of 260F9 showed intermediate activity, with ID $_{\text {so }}$ values in the range of $10-40 \mathrm{ng} / \mathrm{ml}$. The other immunotoxins affected protein synthesis only at high concentrations (ID 50 values $>1,000 \mathrm{ng} / \mathrm{ml}$ ).

The results for A1847 cells are shown in Fig. 6. Again, 454C11-PE was very active, and its toxicity was competable by excess antibody. It required high concentrations of 260F9-PE (or 280D11-PE) to inhibit protein synthesis. The effect of 260F9PE appeared to be nonspecific because it could not be blocked by excess antibody. The ID $_{50}$ values for RTA conjugates were $>1,000 \mathrm{ng} / \mathrm{ml}$. In KB cells (Fig. 7), 260F9-PE, 260F9-RTA, 280D11-PE, and 280D11-RTA inhibited protein synthesis only at concentrations $>100 \mathrm{ng} / \mathrm{ml}$. The toxicity of both $260 \mathrm{~F} 9-\mathrm{PE}$ and 280D11-PE could not be blocked by excess antibody (Fig. 7 and data not shown). However, 454C11-PE inhibited protein synthesis in this cell line, and this effect was also competable by free antibody. KB cells express the antigen recognized by antibody $454 \mathrm{C} 11$ as assessed by indirect immunofluorescence (data not shown). 454C11-RTA showed little activity.

Colony formation assay. Immunotoxins were also studied for their cell-killing ability in a colony formation assay. The results of the colony formation assay reflected the toxicity of the conjugates seen in the protein synthesis inhibition assay. The results with OVCAR-2 cells are shown in Fig. 8. Conjugates of

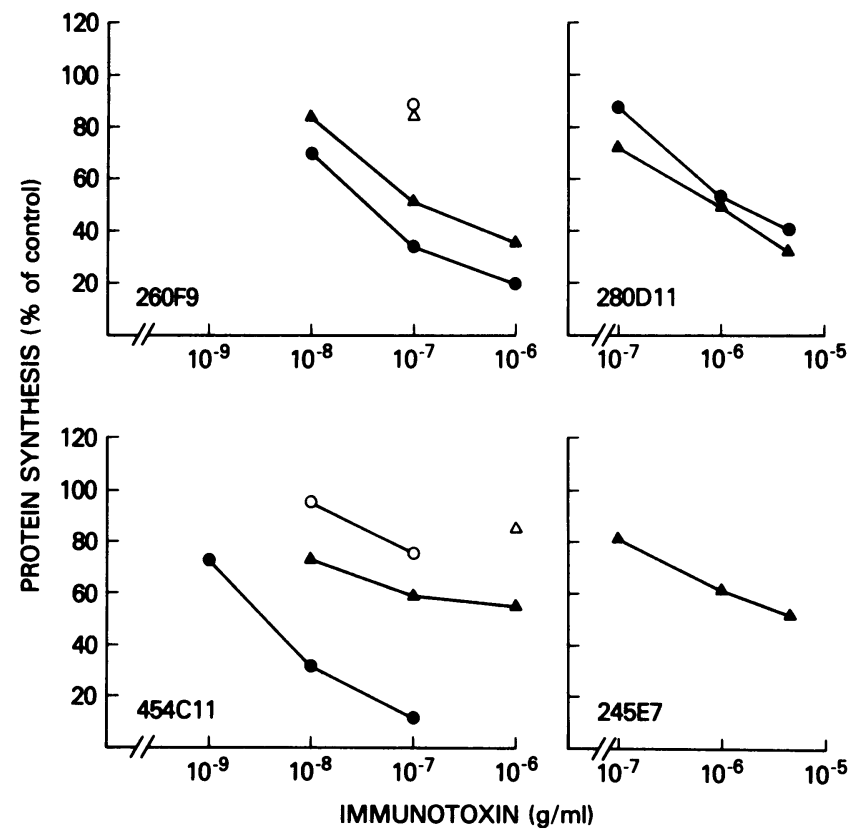

Figure 3. Inhibition of protein synthesis by immunotoxins in OVCAR-3 cells. The experiment was performed as described for Fig. 2. Open symbols represent experiments in which cells were incubated with immunotoxins in the presence of excess antibody as described for Fig. 2. ๑, $\bigcirc$, PE conjugates; $\Delta, \Delta, \mathrm{RTA}$ conjugates.

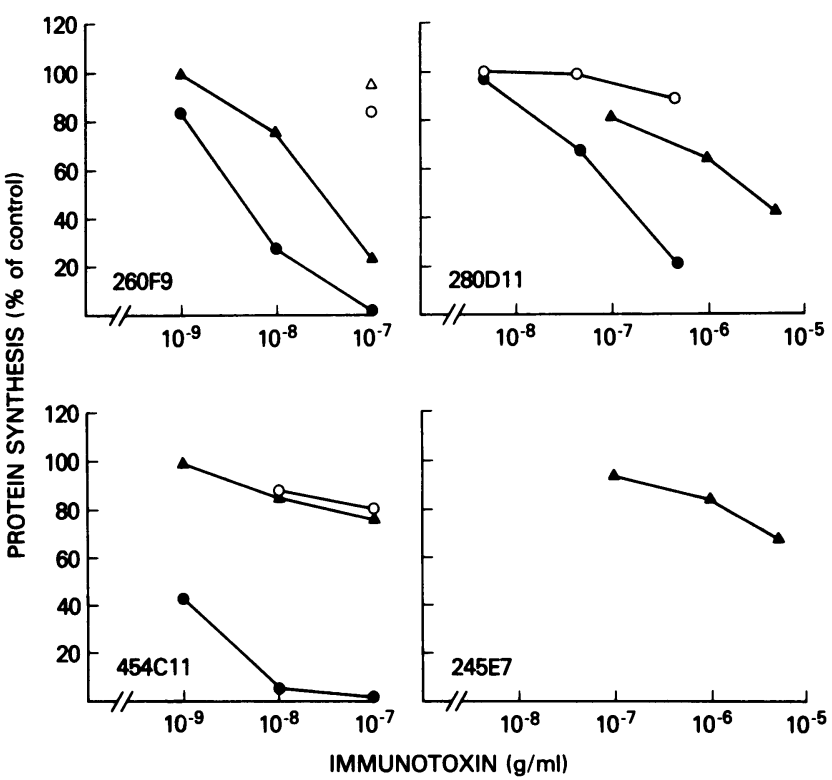

Figure 4. Inhibition of protein synthesis by immunotoxins in OVCAR-4 cells. For experimental details, see legend for Fig. 2. Competition with excess $260 \mathrm{~F} 9$ or $454 \mathrm{Cl} 1$ antibody was performed as described for Fig. 2. For 280D11-PE, competition was done with $50 \mu \mathrm{g} /$ $\mathrm{ml} 280 \mathrm{D} 11$. Open symbols refer to immunotoxins plus excess antibody. $\bullet, \mathrm{O}$, PE conjugates; $\Delta, \Delta, \mathrm{RTA}$ conjugates. 


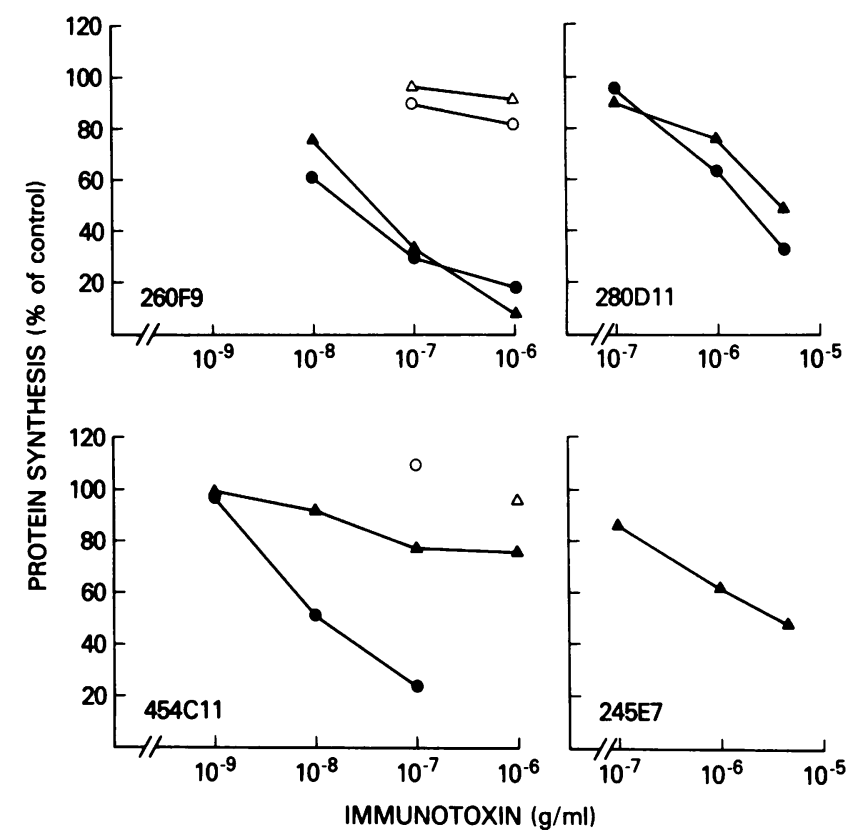

Figure 5. Inhibition of protein synthesis by immunotoxins in OVCAR-5 cells. For experimental details, see legend for Fig. 2. Open symbols refer to inhibition of protein synthesis by immunotoxins in the presence of excess corresponding antibody as described for Fig. 2. $\bullet, O$, PE conjugates; $\Delta, \Delta$, RTA conjugates.

antibody 260 F9 were very efficient immunotoxins, with $50 \%$ inhibition of colony formation at $0.1 \mathrm{ng} / \mathrm{ml} 260 \mathrm{~F} 9-\mathrm{PE}$ and 0.5 $\mathrm{ng} / \mathrm{ml}$ 260F9-RTA, respectively. The toxicity was blocked by excess antibody 260F9. 454C11-PE was slightly more active than the 260F9 conjugates. 280D11-RTA and 245E7-RTA were toxic

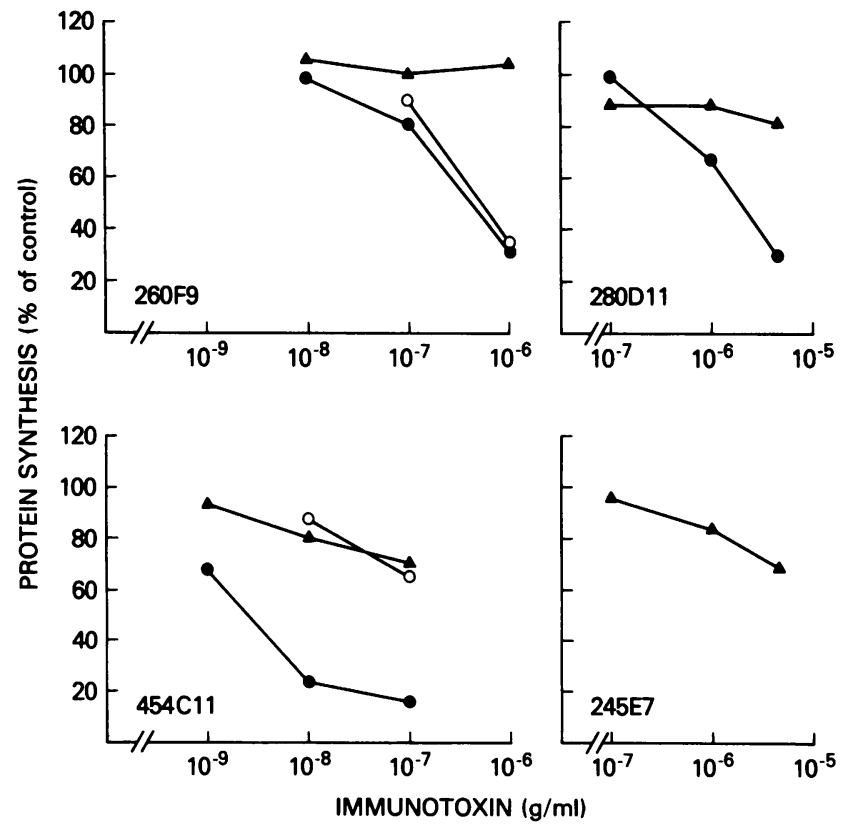

Figure 6. Inhibition of protein synthesis by immunotoxins in A1847 cells. For experimental details, see legend for Fig. 2. Open symbols refer to competition of the activity of immunotoxins by excess corresponding antibody. $\bullet, \mathrm{O}$, PE conjugates; $\Delta$, RTA conjugates.

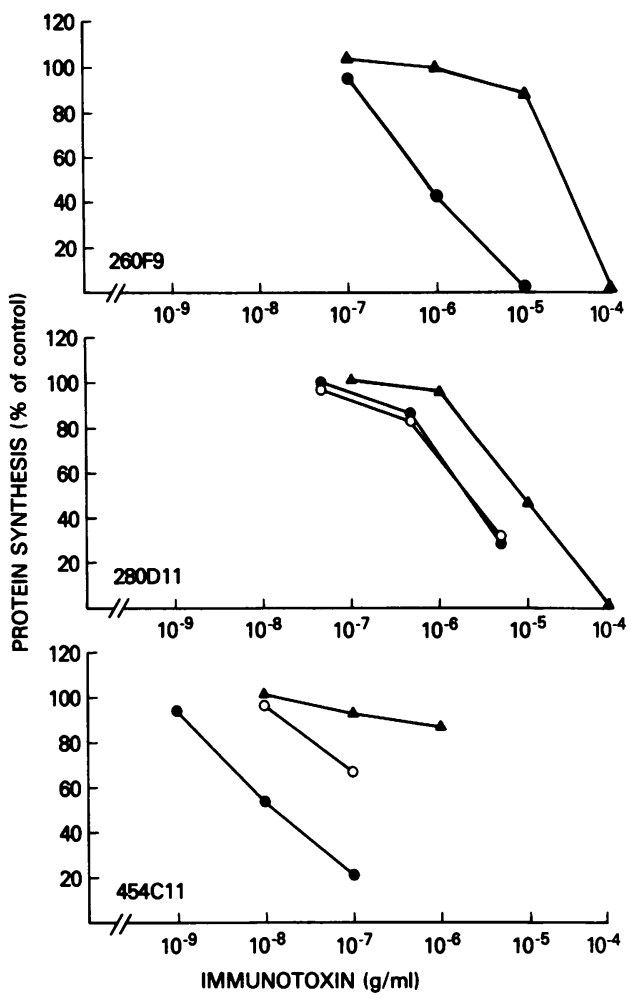

Figure 7. Inhibition of protein synthesis by immunotoxins in KB cells. For experimental details, see legend for Fig. 2. Open symbols refer to competition by excess free antibody as described for Fig. 4. ๑, ०, PE conjugates; $\triangle$, RTA conjugates.

only at very high immunotoxin concentrations, and were $>100$ fold less active than 260F9 conjugates or 454C11-PE.

Average $\mathrm{ID}_{50}$ values of all of the colony formation experiments are summarized in Table II. In the OVCAR cell lines tested, 454C11-PE and conjugates of 260F9 had the highest activity. Also, in this assay, 260F9-PE was more active than 260F9-

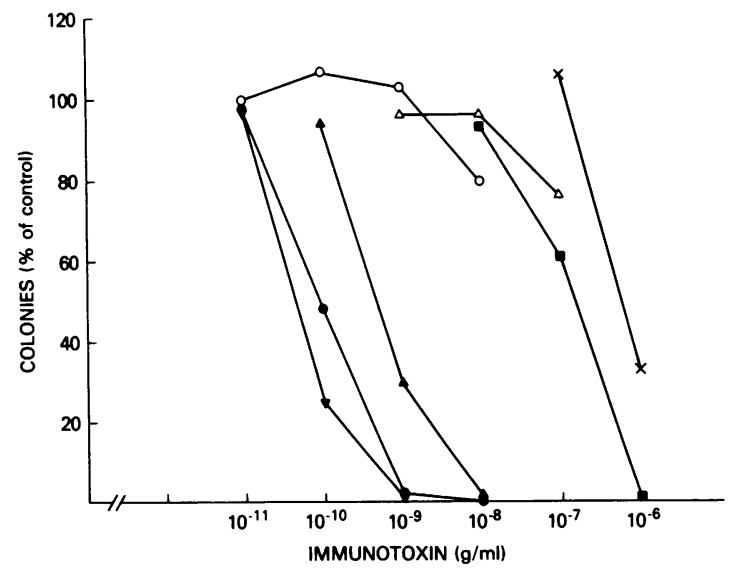

Figure 8. Inhibition of colony formation of OVCAR-2 cells by immunotoxins. Cells ( 500 cells $/ 60$-mm dish) were incubated with various immunotoxins plus or minus excess unconjugated antibody for $13 \mathrm{~d}$, and then the colonies were counted and expressed as percentage of controls that did not receive immunotoxins. $\nabla, 454 \mathrm{C} 11$-PE; $\bullet, 260 \mathrm{F9}$ PE; O, 260F9-PE plus 1,000-fold excess 260F9; $\triangle$, 260F9-RTA; $\triangle$, 260F9-RTA plus 100-fold 260F9; a, 280D11-RTA; ×, 245E7-RTA. 
Table II. ID so Values* for Inhibition of Colony Formation

\begin{tabular}{lccccc}
\hline Cells & 260F9-PE & 260F9-RTA & 454C11-PE & 280D11-RTA & 245E7-RTA \\
\hline OVCAR-2 & 0.1 & 0.7 & 0.05 & 91 & 390 \\
OVCAR-3 & 0.8 & 0.6 & 0.7 & $12 \ddagger$ & ND\$ \\
OVCAR-4 & 0.02 & 0.2 & 0.1 & 24 & $100 \ddagger$ \\
OVCAR-5 & 0.2 & 0.5 & 0.2 & 210 & 107 \\
A1847 & $>10$ & $>80$ & 0.4 & $>1,000$ & $4 \ddagger$ \\
MCF-7 & 0.05 & $4,000 \ddagger$ & 0.8 & $3,600 \ddagger$ & $7 \ddagger$ \\
KB & 210 & & & 0.03 & ND\$
\end{tabular}

500 cells $/ 60-\mathrm{mm}$ dish were incubated with immunotoxins at $37^{\circ} \mathrm{C}$ for $8-14 \mathrm{~d}$. Then, colonies were stained with $0.5 \%$ methylene blue in ethanol/

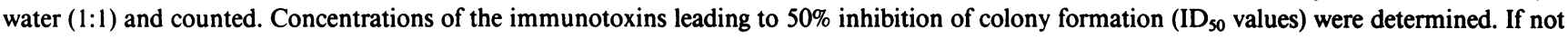
otherwise mentioned, the values shown in the table represent mean values of at least two experiments. * Values are given in nanograms per milliliter. $\ddagger \mathrm{ID}_{50}$ value of one experiment. $\S \mathrm{ND}$, not done.

RTA (except in OVCAR-3). In A1847 cells, 454C11-PE at 0.4 $\mathrm{ng} / \mathrm{ml}$ led to $50 \%$ inhibition of colony formation, whereas the $\mathrm{ID}_{50}$ values for the other immunotoxins were $>10 \mathrm{ng} / \mathrm{ml}$.

Internalization of monoclonal antibodies. In OVCAR-2 cells, 454C11-PE was the most active immunotoxin, followed by 260F9-PE and 260F9-RTA, whereas 454C11-RTA and both conjugates of $280 \mathrm{D} 11$ showed little or no activity. To investigate possible reasons for these different activities, we studied the internalization of the following antibodies in OVCAR-2 cells: 260F9, 280D11, 454C11, and anti-TFR. When studied by indirect immunofluorescence, all these antibodies bound to the cell surface, and there were often quantitative differences in reactivity among cells from a single cell line. Only anti-TFR reacted in a uniform manner with all cells from the same cell line. As shown in Fig. 1, anti-TFR was efficiently internalized, and after a $1-\mathrm{h}$ incubation at $37^{\circ} \mathrm{C}$ a punctate and presumably lysosomal distribution of the antibody was observed (15). Both 260F9 and $454 \mathrm{C} 11$ showed a much brighter surface pattern than anti-TFR at time zero (no warmup). After $1 \mathrm{~h}$ at $37^{\circ} \mathrm{C}$, definite uptake of antibody into vesicles, although less than that observed with anti-TFR, was seen. No internalization of 280D11 antibodies could be detected under the same conditions.

\section{Discussion}

We have identified three immunotoxins that were very active against human ovarian carcinoma cell lines: 454C11-PE was toxic for all five ovarian cell lines studied, whereas 260F9-PE and 260F9-RTA were active in all OVCAR cell lines but not in A 1847 cells. In contrast to these potent immunotoxins, $454 \mathrm{C} 11$ RTA as well as immunotoxins constructed from either 280D11 or 245E7 showed little or no activity towards the ovarian carcinoma cell lines except 280D11-PE in OVCAR-4 (Tables I and II). In a given cell type, the toxicity of the various antibodytoxin conjugates was dependent on both the antibody and the toxin components. Specificity of our active immunotoxins was shown in several ways: (a) Excess antibody competed for the toxicity of the corresponding immunotoxin, indicating that the conjugates bound to the cell surface via the antibody. (b) The immunotoxins had low activity on nontarget cells. In the colony formation assay, OVCAR cells were 260 -fold to 20,000 -fold more sensitive to 260F9-PE or 260F9-RTA than nontarget KB cells (Table II). In addition to our results with KB cells, RTA conjugates of the antibodies used in this study were found to be inactive in two human fibroblast cell lines (10). (c) An irrelevant immunotoxin, such as PE linked to an antibody against the human $T$ cell growth factor receptor (16), has previously been shown to be inactive in the OVCAR cells (7).

Although qualitatively similar results were obtained for both types of assays, ID $_{50}$ values were up to 250 -fold lower in the colony formation assay. One explanation for this finding is that cells exposed longer die because the toxin is catalytic, and even a single molecule in the cytoplasm will eventually kill the cell (17). Because very high concentrations of immunotoxins showed nonspecific inhibition of protein synthesis in $\mathrm{KB}$ cells, the difference in ID $_{50}$ values between target ovarian cells and nontarget $\mathrm{KB}$ cells was less in the protein synthesis inhibition assay than in the colony formation assay where lower immunotoxin concentrations were used.

To be cytotoxic, PE or RTA must be delivered to the cytoplasm, where it can inactivate protein synthesis. In a given cell line, therefore, antibody-dependent differences in toxicity of immunotoxins containing one particular toxin could be due to the differences in rate and extent of antibody internalization. To investigate this, we looked at the cellular uptake of the antibodies by OVCAR-2 cells. Under the conditions used, anti-TFR, 260F9, and $454 \mathrm{C} 11$ were internalized, but 280D11 could not be detected intracellularly. These results could explain why in OVCAR-2 cells PE conjugates of anti-TFR (7), 260F9, or 454C11 were much more toxic than those of 280D11. However, despite internalization of $454 \mathrm{C} 11$, the RTA conjugate of this antibody had low activity, suggesting that additional factors influence the activity of immunotoxins. Nevertheless, poor internalization of an antibody indicates that immunotoxins constructed with this antibody will have low activity.

For a given antibody, PE conjugates were usually more active than their RTA counterparts. These differences may be due to the fact that PE conjugates contain the entire toxin molecule, whereas RTA conjugates lack the B subunit that facilitates membrane permeation (18). However, we cannot exclude the possibility that subtle differences in the disulfide linkage favored the retention of a higher binding affinity by the antibodies when linked to PE.

This study suggests that 454C11-PE, 260F9-PE, and 260F9RTA are potential candidates for therapy of human ovarian carcinoma. Ongoing in vivo studies using a xenograft model of human ovarian carcinoma in nude mice (19) should answer whether sufficient in vivo targeting can be achieved and, additionally, will provide more data on the pharmacokinetics and side effects of these immunotoxins. Finally, it remains to be seen 
whether the activity of these immunotoxins, in particular of the ones with low activity, could specifically be increased by one of the methods reported to enhance the toxicity of immunotoxins (18, 20-25).

\section{Acknowledgments}

We wish to thank Betty Lovelace and Maria Gallo for technical assistance, Ray Steinberg for photographic work, and Dr. Antonio Fojo for critically reading the manuscript. We also wish to thank the following people at Cetus Corp. (Emeryville, CA): Jon Raymond, Tom Batter, and Catherine White for monoclonal antibodies and RTA; David Birch and Jeng Chang for RTA conjugate preparation; Ross Cox and Greg Groetsema for RTA conjugate quality assurance; and Michael Bjorn for useful comments.

Dr. Pirker is on leave from the University of Vienna, Austria, and is the recipient of a Fogarty Fellowship.

\section{References}

1. Köhler, G., and C. Milstein. 1975. Continuous cultures of fused cells secreting antibody of predefined specificity. Nature (Lond.). 256: 495-497.

2. Tsukada, Y., E. Hurwitz, R. Kashi, M. Sela, N. Hibi, A. Hara, and $\mathrm{H}$. Hirai. 1982. Chemotherapy by intravenous administration of conjugates of daunomycin with monoclonal and conventional anti-rat $\alpha$-fetoprotein antibodies. Proc. Natl. Acad. Sci. USA. 79:7896-7899.

3. Gilliland, D. G., Z. Steplewski, R. J. Collier, K. F. Mitchell, T. H. Chang, and H. Koprowski. 1980. Antibody-directed cytotoxic agents: use of monoclonal antibody to direct the action of toxin A chains to colorectal carcinoma cells. Proc. Natl. Acad. Sci. USA. 77:4539-4543.

4. Vitetta, E. S., K. A. Krolick, M. Miyama-Inaba, W. Cushley, and J. W. Uhr. 1983. Immunotoxins: a new approach to cancer therapy. Science (Wash. DC). 219:644-650.

5. Young, R. C., R. C. Knapp, and C. A. Perez. 1982. Cancer of the ovary. In Cancer: Principles and Practice of Oncology. V. T. DeVita, Jr., S. Hellman, and S. A. Rosenberg, editors. J. B. Lippincott Co., Philadelphia. 884-913.

6. Feldman, G. B., R. C. Knapp, S. E. Order, and S. Hellman. 1972. The role of lymphatic obstruction in the formation of ascites in a murine ovarian carcinoma. Cancer Res. 32:1663-1666.

7. Pirker, R., D. J. P. FitzGerald, T. C. Hamilton, R. F. Ozols, M. C. Willingham, and I. Pastan. 1985. Anti-transferrin receptor antibody linked to Pseudomonas exotoxin as a model immunotoxin in human ovarian carcinoma cell lines. Cancer Res. 45:751-757.

8. Gatter, K. C., G. Brown, I. S. Trowbridge, R. E. Woolston, and D. Y. Mason. 1983. Transferrin receptors in human tissues: their distribution and possible clinical relevance. J. Clin. Pathol. 36:539-545.

9. Frankel, A. E., D. B. Ring, F. Tringale, and S. T. Hsieh-Ma. 1985. Tissue distribution of breast cancer associated antigens defined by monoclonal antibodies. J. Biol. Response Modifiers. 4:273-286.

10. Bjorn, M. J., D. Ring, and A. Frankel. 1985. Evaluation of monoclonal antibodies for the development of breast cancer immunotoxins. Cancer Res. 45:1214-1221.
11. Iglewski, B. H., and D. Kabat. 1975. NAD-dependent inhibition of protein synthesis by Pseudomonas aeruginosa toxin. Proc. Natl. Acad. Sci. USA. 72:2284-2288.

12. Olsnes, S., and A. Pihl. 1982. Toxic lectins and related proteins. In Molecular Action of Toxins and Viruses. P. Cohen, and S. van Heyningen, editors. Elsevier Biomedical Press, Amsterdam. 51-105.

13. Hamilton, T. C., R. C. Young, W. M. McKoy, K. R. Grotzinger, J. A. Green, E. W. Chu, J. Whang-Peng, A. M. Rogan, W. R. Green, and R. F. Ozols. 1983. Characterization of a human ovarian carcinoma cell line (NIH:OVCAR-3) with androgen and estrogen receptors. Cancer Res. 43:5379-5389.

14. Hamilton, T. C., R. C. Young, and R. F. Ozols. 1984. Experimental model systems of ovarian cancer: applications to the design and evaluation of new treatment approaches. Semin. Oncol. 11:285-298.

15. Hopkins, C. R., and I. S. Trowbridge. 1983. Internalization and processing of transferrin and the transferrin receptor in human carcinoma A431 cells. J. Cell Biol. 97:508-521.

16. FitzGerald, D. J. P., T. A. Waldmann, M. C. Willingham, and I. Pastan. 1984. Pseudomonas exotoxin-anti-TAC: cell-specific immunotoxin active against cells expressing the human $\mathrm{T}$ cell growth factor receptor. J. Clin. Invest. 74:966-971.

17. Eiklid, K., S. Olsnes, and A. Pihl. 1980. Entry of lethal doses of abrin, ricin and modeccin into the cytosol of HeLa cells. Exp. Cell Res. 126:321-326.

18. Youle, R. J., and D. M. Neville, Jr. 1982. Kinetics of protein synthesis inactivation by ricin-anti-Thy 1.1 monoclonal antibody hybrids. Role of the ricin B subunit demonstrated by reconstitution. J. Biol. Chem. 257:1598-1601.

19. Hamilton, T. C., R. C. Young, K. G. Louie, B. C. Behrens, W. M. McKoy, K. R. Grotzinger, and R. F. Ozols. 1984. Characterization of a xenograft model of human ovarian carcinoma which produces ascites and intraabdominal carcinomatosis in mice. Cancer Res. 44:5286-5290.

20. FitzGerald, D. J. P., I. S. Trowbridge, I. Pastan, and M. C. Willingham. 1983. Enhancement of toxicity of antitransferrin receptor antibody-Pseudomonas exotoxin conjugates by adenovirus. Proc. Natl. Acad. Sci. USA. 80:4134-4138.

21. Akiyama, S., P. Seth, R. Pirker, D. FitzGerald, M. M. Gottesman, and I. Pastan. 1985. Potentiation of cytotoxic activity of immunotoxins on cultured human cells. Cancer Res. 45:1005-1007.

22. Casellas, P., B. J. P. Bourrie, P. Gros, and F. K. Jansen. 1984. Kinetics of cytotoxicity induced by immunotoxins. Enhancement by lysosomotropic amines and carboxylic ionophores. J. Biol. Chem. 259: 9359-9364.

23. Ramakrishnan, S., and L. L. Houston. 1984. Inhibition of human acute lymphoblastic leukemia cells by immunotoxins: potentiation by chloroquine. Science (Wash. DC). 223:58-61.

24. Thorpe, P. E., W. C. J. Ross, A. N. F. Brown, C. D. Myers, A. J. Cumber, B. M. J. Foxwell, and J. T. Forrester. 1984. Blockade of the galactose-binding sites of ricin by its linkage to antibody: specific cytotoxic effects of the conjugate. Eur. J. Biochem. 140:63-71.

25. Vitetta, E. S., R. J. Fulton, and J. W. Uhr. 1984. Cytotoxicity of a cell-reactive immunotoxin containing ricin A chain is potentiated by an anti-immunotoxin containing ricin B chain. J. Exp. Med. 160:341346. 